Original Article

\title{
To Determine the Plasma Levels of Malondialdehyde in Patient with Pre-eclampsia and Healthy Pregnant Women of Hyderabad, Sindh
}

\author{
Farheen Shaikh, Sanum Ali Dahri, Ali Raza Memon, Ayaz Ali Memon, \\ Muhammad Yousuf Memon, Giran Naz Jagirani
}

ABSTRACT

OBJECTIVES: Pre-eclampsia is leading cause of maternal mortality and morbidity throughout the world. In Pakistan the mortality rate of pregnancy related problems is estimated to be approximately $\mathbf{5 0 0}$ per 100,000 live births. According to several studies oxidative stress and production of free radicles may be responsible for abnormal development of placenta results in the pathogenesis of pre-eclampsia. During oxidative stress Malondialdehyde has been proposed as novel factors concerned in development of pre-eclampsia.

METHOD: Total 210 voluntaries were taken for the study, from which $\mathbf{5 0}$ voluntaries were normotensive healthy pregnant women as a control, 160 were patient with pre-eclampsia as cases. The subjects were recruited after taking obstetric history, anthropometric and clinical data. After taking informed consent, blood sample collected and stored for biochemical analysis. Malondialdehyde was analyzed on spectrophotometer. The study was conducted in Biochemistry Department Liaquat University of Medical \& Health Sciences, Jamshoro from February 2015 to October 2015.

RESULTS: Two hundred and ten subjects were included in this study. The Mean \pm S.D of age of controls and pre-eclamptic subjects were noted as $27.5 \pm 4.5$ and $27.38 \pm 4.3$ years. Gestational ages of controls were $25.76 \pm 4.35$ and cases were noted as $27.37 \pm 4.49(p<0.053)$. The mean difference of serum Malondialdehyde levels in controls were $1.54 \pm 0.28 \mathrm{nmol} / \mathrm{dl}$, while in pre-eclamptic subjects it was $2.42 \pm 0.63 \mathrm{nmol} / \mathrm{dl}$ which is highly significant and $\mathrm{p}<0.05$ respectively.

CONCLUSION: Malondialdehyde is index marker of lipid peroxidation. Increased formation of free radicles due to increased concentration of Malondialdehyde may put forward the possible involvement in the pathology of PE. The aim of this study to protects the mothers as well as her coming newborn from such life threatening disease.

KEYWORDS: Malondialdehyde, Lipid peroxidation, Pre-eclampsia (PE), Uv-Spectrophotometer

This article may be cited as: Shaikh F, Dahri SA, Memon AR, Memon AA, Memon MY, Jagirani GN. To Determine the Plasma Levels of Malondialdehyde in Patient with Pre-eclampsia and Healthy Pregnant Women of Hyderabad, Sindh. J Liaquat Uni Med Health Sci. 2018;17(02):86-90. doi: 10.22442/jlumhs. 181720556

\section{INTRODUCTION}

Pre-eclampsia (PE) is a pregnancy related complication occurs after the 20th week of pregnancy with systolic blood pressure of $140 \mathrm{~mm}$ of $\mathrm{Hg}$ or diastolic blood pressure of $90 \mathrm{mmHg}$ or more, taking two readings six hours apart accompanied by significant proteinuria $300 \mathrm{mg}$ or more in 24 hours urine collection ${ }^{1,22}$. According to World Health Organization (WHO) the incidence of PE in 2014 was $19 \%$ in developing countries, $35 \%$ in Pakistan, $33 \%$ in India, $28 \%$ in Africa and $23 \%$ in South America ${ }^{21}$. Pathogenesis of $P E$ and its causative factors are still unclear. Many researchers proposed that it is developed due to endothelial cell injury, which produced oxidative species resulting in uncontrolled lipid peroxidation (LPO) ${ }^{2}$. Endothelial dysfunction also leads to cause impairment of nitric oxide pathway, causes reduced blood flow and poor placentation ${ }^{13}$. Oxidative stress is an imbalance between production of free radicals and antioxidants which leads to cause potential damage to the cell. In normal condition free radicals and antioxidants are in balance ${ }^{12}$. Oxidative stress is increased throughout pre-eclampsia, resulting in enhanced production of lipid peroxides ${ }^{22}$. Metabolic changes and inflammation increases the oxidative stress by producing reactive oxygen species and Nitric oxide radicals ${ }^{13}$.

Malondialdehyde (MDA) is an indicator of lipid peroxidation (LPO). MDA is three carbon aldehyde and break down products, produces free radicals which act on polyunsaturated fatty acid of lipid bilayer $^{3}$. Lipid peroxidation is harmful to the cell 
membrane because it acts as self- perpetuating reaction, Lipid peroxidation decreases the membrane potential by loss of fluidity and increased permeability to calcium ions and protons, which break down cell membrane ${ }^{6}$. Malondialdehyde is increased in many diseases but greatly increased in pregnancy-induced hypertension. Oxidative stress can produce interrelated derangements of cell metabolism.There are three phases of lipid peroxidation Initiation, propagation and termination?

The end products of lipid peroxidation are reactive aldehydes, such as MDA and 4-hydroxynonenal (HNE). Lipid peroxidation it self amplifies for the formation of free radicals, single initiation event can results in conversion of hundreds of fatty acid side chains into lipid hydroperoxides ${ }^{8,10}$. When MDA level increases, produce free radicals which damages the cell membrane and also have strong association with severity of disease ${ }^{20}$. MDA also effect on DNA and causes oxidative stress by production of free radicals. The normal levels of Plasma MDA is $1.40-1.90 \mathrm{nmol}$ dl, MDA levels increases throughout pregnancy but more in pre-eclampsia ${ }^{14}$.

\section{PURPOSE OF STUDY}

This study was conducted to evaluate the plasma levels of MDA in healthy pregnant women and compare with patients of pre-eclampsia, thus present study may be helpful to early diagnosis to pre-eclampsia.

\section{OBJECTIVE OF STUDY}

- To estimate the plasma levels of Malondialdehyde in healthy pregnant women and patient with pre-eclampsia.

- To compare the plasma levels of Malondialdehyde in healthy pregnant women and patient with pre-eclampsia.

\section{SETTING}

The study is conducted in Biochemistry Department, Liaquat University of Medical \& Health Sciences, Jamshoro and patients were recruited from Department of Obstetrics \& Gynecology, Liaquat University Hospital Jamshoro/Hyderabad.

\section{SAMPLE SIZE}

The sample size calculation was done according to general calculation formula. Pre-eclampsia ${ }^{22}$ is $5 \%$ by using the proportion of $95 \%$ confidential interval and $5 \%$ margin of error, the sample size calculated was $n$ $=80$.

Total 210 subjects were recruited and divided into two groups.
Group A: $n=50$ Healthy pregnant women with normal B.P after 20 weeks of gestation and Group B: $n=160$ patients with pre-eclampsia after 20 weeks of gestation

STUDY DESIGN: Cross-sectional, Comparative study.

STUDY DURATION: Within eight months after approval of study from Ethical Review Committee of LUMHS Jamshoro.

INCLUSION CRITERIA: Healthy pregnant women after 20 weeks of gestation. Pregnant women with pre -eclampsia after 20 weeks of gestation, age in between $20-35$ years.

EXCLUSION CRITERIA: Pregnant women below 20 or above 35 years, Multiple Pregnancy Known hypertensive, diabetic, cardiac and renal patients, any liver disease, Smokers. Any use of drug.

\section{METHODOLOGY}

The study comprised on two phases. Phase 1 was recruitment of volunteers and phase 2 was collecting blood samples from the volunteers with 12-14 hours fasting. Population informed for the recruitment by the flyers at Department of Obstetrics and Gynecology, Jamshoro/Hyderabad.

\section{BLOOD PARAMETERS}

About $03 \mathrm{ml}$ of blood was collected from each participant by venopuncture into vacationers under aseptic measures, collected into EDTA test tube for MDA. The blood was centrifuged at $3500 \mathrm{rpm}$ for 5 min by centrifuged machine; the plasma was fractionated and transferred to eppendorf cups then stored at $-20^{\circ} \mathrm{C}$ till required for analysis. Before the analysis sample was first allowed to attain room temperature then used.

\section{DATA COLLECTION}

For this study, all clinical data and relevant details of each participant was registered by filling a Performa or Questionnaire. Verbal and written consent was taken from all participants, explaining them about study purpose.

\section{ETHICAL CONSIDERATION}

The study was conducted strictly under the ethical rules after the approval from Ethical Review Committee of LUMHS Jamshoro.

\section{STATISTICAL ANALYSIS PROCEDURE}

Data was entered in Microsoft Excel and analyzed on SPSS (Statistical package for Social Sciences) Version 16. Student t-test for comparison between cases and controls were used for continuous variables. Results were presented as mean and standard deviation.

EXPERIMENTAL PROTOCOL: Malondialdehyde 
procedure was performed on spectrophotometer UV 1650 PC SHIMADZU.

ESTIMATION OF MALONDIALDEHYDE: Chemicals and Reagents such as, methanol

Trichloroacetic acid (TCA), Orthophosphoric acid $\left(\mathrm{H}_{3} \mathrm{PO}_{4}\right)$, Thiobarbituric acid (TBA), Sulfuric acid $\left(\mathrm{H}_{2} \mathrm{SO}_{4}\right)$ and Standard of MDA 1, 1, 3, 3- Tetraethoxypropane (TEP). All chemicals and reagents were of analytical grade and purchased from SigmaAldrich.

STANDARD PREPARATION: 1, 1, 3, 3- Tetraethoxypropane (TEP) was used as standard. For the preparation of stock solution, taken $25 \mu \mathrm{l}$ TEP dissolved in $100 \mathrm{ml}$ of distilled water to give $1 \mathrm{mM}$ stock solution. Working standard was prepared by hydrolysis of $1 \mathrm{ml}$ TEP stock solution in $50 \mathrm{ml} 1 \%$ sulfuric acid, left at room temperature for two hours, protected the mixture from the light and keeps it at $-20^{\circ} \mathrm{C}$ for 18 months.

To determine the different concentration of standard used 0 as blank (distilled water), standard of 5, 10 and $20 \mathrm{nmol} / \mathrm{ml}$ TEP were used.

ESTIMATION OF MDA BY THIOBARBITURIC ACID METHOD

\section{PROCEDURE}

$100 \mu \mathrm{l}$ of plasma and $25 \mu \mathrm{l} 3 \mathrm{M} \mathrm{NaOH}$ was taken in test tube. The tubes were capped, vertexes and placed in water bath at $60^{\circ} \mathrm{C}$ for 30 minutes. For the hydrolysis, $1 \mathrm{ml}$ of sulfuric acid and $0.5 \mathrm{ml} 20 \%$ TCA were added then centrifuged at $3000 \mathrm{rpm}$ for 5 inutes then added $1 \mathrm{ml}$ of TBA in the test tube. $1 \mathrm{ml}$ of supernatant layer was removed and again kept in water bath for 30 minutes. Upon cooling the mixture rapidly centrifuged at $3000 \mathrm{rpm}$ for 10 minutes and analyzed for Malondialdehyde levels on UV-spectrophotometer at $532 \mathrm{~nm}^{14,15}$.

\section{RESULTS}

The results of present study was carried out to evaluate the significance of plasma Malondialdehyde in pre-eclampsia and the results are taken as (mean $\pm S D$ ) summarized in Table-I and presented in graph-I. Total 210 subjects were included in this study, 50 were normotensive pregnant women and 160 were patients with pre-eclampsia. Maternal age of normal pregnant healthy women was $(26.5 \pm 4.28)$ weeks and pre-eclamptic subjects were $(26.38 \pm 5.16)$ weeks respectively. Gestational ages of controls and cases were $\left(\begin{array}{lll}28.76 & \pm 4.48\end{array}\right)$ and $(27.37 \quad \pm 4.49)$ years respectively which are insignificant $(p<0.05)$ as shown in table I \& presented in graph I.

Systolic blood pressure (mean $\pm S D$ ) in controls were noted as $(113.2 \pm 9.13) \mathrm{mmHg}$, while in pre-eclamptic it was $(175.9 \pm 2.59) \mathrm{mmHg}$ showing statistically significant. Diastolic B.P in controls were noted as $(74.40 \pm 6.75) \mathrm{mmHg}$ and pre-eclamptic subjects $(110.5 \pm 9.75) \mathrm{mmHg}$ was highly significant $(p<0.05)$ as shown in table-1 and presented in graph 1 respectively.

The Plasma Malondialdehyde levels (mean \pm SD) in controls were $(1.54 \pm 0.28) \mathrm{nmol} / \mathrm{d}$ and in pre-eclamptic subjects $(2.42 \pm 0.63) \mathrm{nmol} / \mathrm{dl}$. The plasma Malondialdehyde levels were significantly higher ( $p$ $<0.05$ ) in pre-eclamptic patients as against the control subjects, values were shown in Table I and graphically represented in graph II.

TABLE I: COMPARISON OF AGE, GESTATIONAL AGE, SYSTOLIC, DIASTOLIC BLOOD PRESSURE AND MALONDIALDEHYDE BETWEEN CONTROLS AND CASES

\begin{tabular}{|l|c|c|l|}
\hline \multirow{2}{*}{ VARIABLES } & $\begin{array}{c}\text { Control } \\
(\mathbf{5 0 )}\end{array}$ & $\begin{array}{c}\text { Cases } \\
(\mathbf{1 6 0 )}\end{array}$ & \multirow{2}{*}{ p- Value } \\
\cline { 2 - 4 } & Mean \pm S.D & Mean \pm S.D & \\
\hline Age (years) & $26.5 \pm 4.28$ & $26.38 \pm 5.16$ & $\leq 0.05^{\star}$ \\
\hline $\begin{array}{l}\text { Gestational } \\
\text { Age (Weeks) }\end{array}$ & $28.76 \pm 4.48$ & $27.37 \pm 4.45$ & $\leq 0.05^{\star}$ \\
\hline $\begin{array}{l}\text { Systolic B.P } \\
\text { (mmHg) }\end{array}$ & $113.2 \pm 9.13$ & $175.9 \pm 2.59$ & $\leq 0.05^{\star}$ \\
\hline $\begin{array}{l}\text { Diastolic B.P } \\
\text { (mmHg) }\end{array}$ & $74.40 \pm 6.75$ & $110.5 \pm 9.75$ & $\leq 0.05^{\star}$ \\
\hline MDA (nmol/l) & $1.54 \pm 0.28$ & $2.42 \pm 0.63$ & $\leq 0.05^{\star}$ \\
\hline
\end{tabular}

The values are expressed as mean \pm standard deviation and units are given in parenthesis. Results are presented as $p$ values and calculated by student t-test ${ }^{\star} p<0.05,{ }^{\star \star} \mathrm{p}<0.01$

GRAPH I:

COMPARISON OF MATERNAL AGE, GESTATIONAL AGE, SYSTOLIC AND DIASTOLIC BLOOD PRESSURE BETWEEN CONTROLS AND CASES

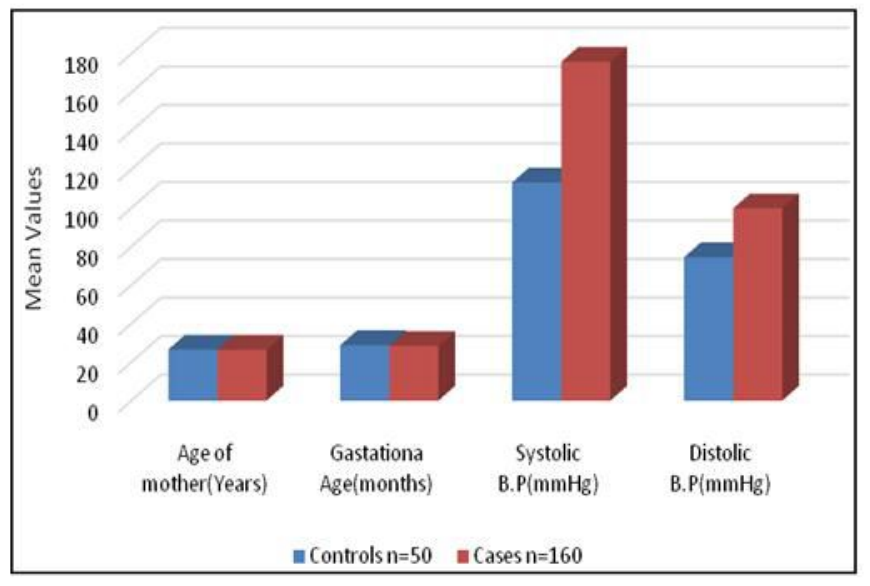




\section{GRAPH II: COMPARISON OF MALONDIALDEHYDE BETWEEN HEALTHY PREGNANT WOMEN WITH PRE- ECLAMPTIC SUBJECTS}

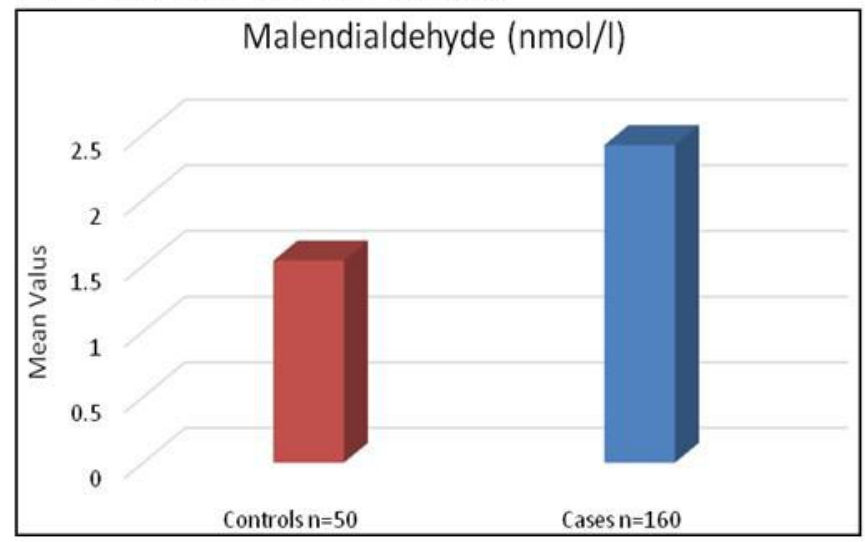

\section{DISCUSSION}

The purpose of this study was to evaluate the role of Malondialdehyde, an oxidative stress marker in patients with pre-eclampsia. Many studies had been reported on the Malondialdehyde levels in pre-eclamptic women ${ }^{17}$. The incidence of preeclampsia is rising in developing countries day by day and pregnant ladies have been suffering by this life threatening disease ${ }^{9,11}$. Specific marker of oxidative stress is Malondialdehyde. It is ultimate product of oxidative disintegration of polyunsaturated fatty acids and is commonly considered as oxidative stress biomarker ${ }^{18}$. Aksoy $\mathrm{H}$ et al. ${ }^{3}$ had reported that Malondialdehyde levels were increased in patients of pre-eclampsia which lead to cause oxidative stress due to increased production of free radicals. In present study results shows that oxidative stress occurs due to increased levels of Malondialdehyde which effect on cellular functions.

Saxena $S$ et $a l .^{19}$ had reported strong and significant relationship between Malondialdehyde and blood pressure. Malondialdehyde effects on blood pressure due to increased generation of oxygen radical species and reduction in antioxidants. In our study plasma Malondialdehyde levels increased significantly in pre-eclamptic women as compared to control subjects.

Atamer $Y$ et $a l^{4}$ had reported that normally free radicals and antioxidants are in balance but in pre-eclampsia this balance distressed which causes oxidative stress resulting in enhance production of free radicals causes excessive consumption of antioxidants, which includes vitamins A, ascorbic acid, trocopherol and antioxidants enzymes such as glutathione peroxidase and superoxide dismutase $e^{5}$. These findings are supporting the present study as well as we observed similar imbalance effects of oxidative stress and antioxidants (by analyzed MDA) in patient with pre-eclampsia.

Gohil JT et al. ${ }^{9}$ observed that during normal pregnancy Malondialdehyde levels were increased and gradually more increased in pre-eclampsia patients as compare to non-pregnant. In our study it was found that Malondialdehyde levels in healthy pregnant women are in normal but significantly increase in pre-eclamptic patients.

Rafeeinia $A$ et $a l^{16}$ had reported that an increase levels of Malondialdehyde in patient with pre-eclampsia is feature of uncontrolled oxidative stress which contribute in development of hypertension in pregnancy. This study is favoring the present study that MDA is increasing in pre-eclamptic patients and may play a role in pathophysiology of pre-eclampsia.

\section{CONCLUSION}

The present study showed increased Malondialdehyde levels in pre-eclamptic patient as compared to the normal healthy pregnant women. The oxidative stress increases and present study analyzed by index marker of lipid peroxidation such as Malondialdehyde. MDA can be used as biomarker for early diagnosis of preeclampsia.

\section{RECOMMENDATION}

Further studies are recommended to confirm the findings of present study and also emphasis other factors of lipid peroxidation which may causes the preeclampsia.

\section{ACKNOWLEDGEMENT}

Authors would like to thanks to participant who cooperated during study and special thanks for the National center of Excellence in Analytical Chemistry, University of Sindh, Jamshoro, who helped us during analysis.

\section{REFERENCES}

1. Adeniji AO, Oparinde DP. Comparison of Lipid Peroxidation and Anti-Oxidant Activities in Pre-Eclamptic; Normal Pregnancies in Nigerian Population. IJCM. 2013; 4(5):239-43.

2. Atiba AS, Abbiyesuku FM, Niran-Atiba TA, Oparinde DP, Ajose OA, Akindele RA. Free Radical Attack on Membrane Lipid and Antioxidant Vitamin in the Course of Pre-eclamptic Pregnancy. Ethiop J Health Sci.2014; 24(1):35-42.

3. Aksoy $\mathrm{H}$, Ozkan A, Aktas $\mathrm{F}$, Borekci B. Helicobacter pylori seroposivity and its relationship with serum malondialdehyde and lipid profile in preeclampsia. J Clin Lab Anal. 2009; 23 (4):219-222.

4. Atamer $\mathrm{Y}$, Kocyigit $\mathrm{Y}$, Yokus $\mathrm{B}$, Atamer A, Erden 
AC. Lipid peroxidation, antioxidant defense, status of trace metals and leptin levels in preeclampsia. Eur J Obstet Gynecol Reprod Biol. 2005; 119 (1):60-6.

5. Bakacak M, Kilinc M, Serin S, et al. Changes in Copper, Zinc, and Malondialdehyde levels and Superoxide Dismutase activities in Pre-Eclamptic Pregnancies. Med Sci Monit. 2015; 21:24142420.

6. Halliwall B, Chirico S. Lipid Peroxidation: Its Mechanism, Measurement and Significance. Am J Clin Nutr, 1993; 57(5 Suppl): 715S-724S.

7. Bhagat S, Patra PK, Thakur AS. Association of Inflammatory Biomarker C-Reactive Protein, Lipid Peroxidation and Antioxidant Capacity Marker with $\mathrm{HbF}$ Level in Sickle Cell Disease Patients from Chattisgarh. Indian J Clin Biochemistry. 2012; 27(4): 394-399.

8. Schneider C. An Update on Products and Mechanism of Lipid Peroxidation. Mol Nutr Food Res. 2009; 53(3): 315-21.

9. Gohil. JT, Patel PK, Gupta P. Evaluation of Oxidative Stress and Antioxidant Defense in Subjects of pre-eclampsia. J Obstet Gynecol India.2011; 61(6):638-40.

10. Moselhy HF, Reid RG, Yousef S, Boyle SP. A Specific, Accurate and Sensitive Measure of Total Plasma Malondialdehyde by HPLC. J Lipid Res 2013; 54(3): 852-8.

11. Robert JM, Bell MJ. If We Know So Much About Pre Eclampsia, Why Haven't We Cured The Disease?. J Reprod Immunol. 2013; 99(0): 1-9.

12. Johnkennedy N, Augustin I, Ifeoma U. Alterations in antioxidants enzymes and Malondialdehyde status in preeclampsia. Asian Pacific Journal of Tropical Biomedicine. 2012; 2(2):S750-S752.

13. Matsubara K, Higaki T, Matsubara U, Nawa A. Nitric Oxide and Reactive Oxygen Species in the
Pathogenesis of Preeclampsia. Int $\mathrm{J}$ Mol Sci. 2015; 16(3): 4600-4614.

14. Khoubnasabjafar M, Ansarin K, Jouyban A. Critical review of malondialdehyde analysis in biological samples. Cur Pharm Anal. 2015;16:4-17

15. Ohkawa H, Ohishi N, Yagi K. Assay for lipid peroxides in animal tissues by thiobarbituric acid reaction. Anal Biochem. 1979; 95:351-358.

16. Rafeeinia A, Tabandeh A, Khajeniazi S, Marjani AJ. Serum copper, zinc and lipid peroxidation in pregnant women with preeclamepsia in Gorgan. Open Biochem J. 2014; 8:83-88.

17. Patil SB, Kodliwadmath MV, Kodliwadmath SM. Correlation between Lipid Peroxidation and Non-Enzymatic Antioxidants in Pregnancy Induced Hypertension. Indian J Clin Biochem. 2008; 23(1): 45-48.

18. Gupte S, Wagh G. Pre-eclampsia- Eclampsia. J Obstet Gynecol India. 2014; 64(1):4-13.

19. Saxena S, Srivastava PC, Thimmaraju KV, Mallick AK. Study of serum Malondialdehyde and uric acid in pregnancy induced hypertension \& its medico-legal significance. J Indian Acad Forensic Med 2014; 36(1):55-60

20. Suresh DR, Annam V. Lipid Peroxidation and Total Antioxidant Capacity in Health and Disease Pathophysiology and Markers: An Overview. Int J Med Sci Public Health. 2013; 2(3): 478-9.

21. Shamsi U, Saleem S, Nishter N. Epidemiology and risk factors of preeclampsia; an overview of observational studies. Al Ameen J Med Sci. 2013; 6(4):292-300.

22. Shaikh F, Shah T, Ansari S, Dahri S. To Determine the Role of Co-Enzyme Q10 and Trace Elements in Patient with Pre-Eclampsia - A Cross Sectional Study inHyderabad. J Liaquat Uni Med Health Sci. 2017; 16(2):86-92. doi: 10.22442/ jlumhs. 171620512

\begin{tabular}{|ll|}
\hline AUTHOR AFFILIATION: & Dr. Ali Raza Memon \\
Dr. Farheen Shaikh (Corresponding Author) & Department of Biochemistry \\
Department of Biochemistry & LUMHS, Jamshoro, Sindh-Pakistan. \\
Liaquat University of Medical and Health Sciences & Dr. Ayaz Ali Memon \\
(LUMHS), Jamshoro, Sindh-Pakistan. & National Center of Excellence in Analytical Chemistry \\
Email: shaikhfarheen14@gmail.com & University of Sindh, Jamshoro, Sindh-Pakistan. \\
& Dr. Muhammad Yousuf Memon \\
Dr. Sanum Ali Dahri & Department of Biochemistry \\
Department of Anatomy & LUMHS, Jamshoro, Sindh-Pakistan. \\
Basic Medical Sciences & Dr. Giran Naz Jagirani \\
Institute Jinnah Postgraduate Medical Centre & Final Year MBBS \\
Karachi, Sindh-Pakistan. & Bahria University Medical \& Dental College, Karachi. \\
\hline
\end{tabular}

